\title{
XIV COLÓQUIO EUROPEU DE GEOGRAFIA TEÓRICA E QUANTITATIVA (ECTQG'05)
}

\author{
Paulo Morgado ${ }^{1}$ \\ JORGE ROCHA ${ }^{1}$
}

O Colóquio Europeu de Geografia Teórica e Quantitativa (ECTQG - European Colloquium of Theoretical and Quantitative Geography) é um evento mundial. Parece uma contradição, mas não é. O ECTQG permite, a investigadores europeus e de fora da Europa, a troca de experiências e conhecimentos sobre o que de mais inovador se tem feito no domínio da geografia neopositivista. Desde o primeiro colóquio, em 1978 em Estrasburgo, até ao último, de 2005, realizado em Tomar, muitas foram as temáticas abordadas que sublinham a corrente de estudo e investigação, duma Geografia aplicada, muito apoiada nas ciências exactas e de cálculo, mas sem esquecer a ligação às Humanidades, porque o sentido de servir a sociedade esteve sempre presente nas preocupações do geógrafo.

Realizado de dois em dois anos, normalmente em cidades pequenas, o ECTQG não é um evento exclusivo aos geógrafos; antes pelo contrário, incentiva-se o contributo e participação de todos aqueles que se interessam e ou praticam geografia(s). É comum o envolvimento de especialistas de domínios das engenharias (engenharia geográfica, engenharia civil, engenharia informática e das telecomunicações), economistas, matemáticos e físicos, entre outros, que integram nos seus estudos e trabalhos de investigação a dimensão espacial e as relações Homem e Meio. Normalmente, o evento perdura por um período de 5 dias, no decurso dos quais se expõem os resultados das investigações feitas e se redefinem as fronteiras do conhecimento geográfico.

O XIV ECTQG realizou-se no mês de Setembro de 2005, e foi, até à data, o de maior sucesso. Para que se possa compreender as razões a que se deveu este sucesso, tentamos aqui relatar, de uma forma sintética e objectiva, o que se passou, do que tratou, e qual a sua importância para a Geografia. Comecemos pelos responsáveis. O XIV ECTQG foi organizado pelo e-Geo - Centro de Estudos de Geografia e Planeamento Regional, da Faculdade de Ciências Sociais e Humanas da Universidade Nova de Lisboa, e por uma metódica equipa que, sob a coordenação do Professor Doutor José António Tenedório (Presidente do e-Geo) e do Professor Doutor Rui Pedro Julião (Vice-Presidente do eGeo), permitiu que este ECTQG desse, mais uma vez, mostras do importante contributo da geografia quantitativa para a compreensão dos fenómenos complexos que caracterizam o território, bem como para o desenvolvimento dos sistemas de apoio à decisão.

1 Investigadores do Centro de Estudos Geográficos e Assistentes do Departamento de Geografia da Faculdade de Letras da Universidade de Lisboa.Email: pms@ceg.ul.pt e jrocha@ceg.ul.pt 
O XIV ECTQG, em números, significa o envolvimento directo de 221 autores, 132 participantes oriundos de vários países (França, Itália, Holanda, Inglaterra, Austria, Bélgica, Suécia, Escócia, Grécia, Japão, China, Israel, Alemanha, Dinamarca, Canadá, Bélgica, Polónia, República Checa e China), 99 artigos distribuídos por 2 sessões paralelas e 11 temas, dos quais importa explicar a essência.

No caso dos autómatos celulares e sistemas multiagentes, expressou-se a preocupação na análise multiescala e multitempo, de fenómenos como a evolução do uso do solo, urbanização, desenvolvimento sustentável e modelação de questões sociais.

$\mathrm{Na}$ temática da análise fractal, obtivemos ecos do rejuvenescimento do estudo da paisagem pelos geógrafos, mas também na análise da morfologia urbana, e da forma como a geometria fractal pode explicar a estrutura urbana e socio-económica.

Sobre desenvolvimento regional e urbano, ficaram os apontamentos da curiosidade pelo estudo da geografia dos modelos, agora renovada sob o epíteto de geomodelação, apoiada na simulação permitida pela computação (geocomputação, geosimulação, ...), no estudo de redes (geografia das redes, retomada dos estudos de Peter Hagget, de 1969, e que tão bem se aplicam hoje à geografia dos transportes e das telecomunicações) e de clusters tecnológicos e de inovação.

A sessão dos Sistemas de Informação Geográfica foi marcada pela temática do ambiente, com a preocupação evidente ao nível da gestão dos recursos naturais, riscos e da poluição, assim como a temática da análise espacial, com artigos a testemunharem quer uma abordagem mais clássica e aplicativa, sobretudo em estruturas de dados raster, mas também no desenvolvimento de novos métodos e algoritmos, e na interação com a estatística multivariada.

A temática da detecção remota também foi abordada. Com pergaminhos nos métodos de trabalho dos geógrafos e nos trabalhos de Geografia, a detecção remota, pela quantidade e qualidade dos artigos submetidos, mereceu uma sessão individual, em que foram feitas comunicações de dois tipos: umas de âmbito mais teórico, sobre a cientificidade da detecção remota e os processos evolutivos que tem sofrido ao longo dos tempos, e outra mais técnica e metodológica, em que se fez apelo à sua capacidade de monitorização dos sistemas. Neste âmbito, as exposições foram sobre a vantagem da aplicação da classificação e processamento de imagens ao estudo de diversos fenómenos (mudanças climáticas, incêndios florestais, dinâmica do litoral, evolução do uso e ocupação do solo, ciclos vegetativos, etc.).

Por último, também a merecer destaque, uma sessão dedicada à análise estatística, modelos matemáticos e topologia. Aqui a discussão desenvolveu-se sobre o formalismo em geografia quantitativa, a procura de padrões espaciais, teoria da geoestatística, dos modelos por detrás da Lei de Zip. A análise espacial e a complexidade foram dois dos principais temas discutidos, em que foram apresentadas virtudes e defeitos de métodos como a lógica fuzzy, teoria de bayes, análise multivariada, redes neuronais supervisionadas e não supervisionadas (self organizing maps), para determinar novas tipologias e constelações espaciais, em sistemas multi-agentes, de comportamento dinâmico, como é o caso do espaço urbano.

Dada a importância que este evento científico tem para a Geografia, o Centro de Estudos Geográficos da Universidade de Lisboa não podia deixar de estar presente. Para além de ter estado representado oficialmente na sessão de abertura, a convite da organização, contribuiu com a apresentação de alguns resultados dos trabalhos dos seus investigadores, sobre o uso de métodos de análise espacial, com recurso aos autómatos celulares, redes neuronais e análise estatística multivariada na determinação de 
padrões espaciais de competitividade e na simulação prospectiva de evolução do uso. Como nota final, quem coordena e gere este projecto. Desde o princípio (década de 70) coordenado por Denise Pumain (actualmente Professora da Universidade Paris I; directora do laboratório Geografia-cidades e directora científica da revista electrónica cybergeo: http://www.cybergeo.presse.fr/) e de sempre apadrinhado por Manfred Fisher (actualmente, Professor e Director do Departamento de Geografia Económica e Geoinformática da Universidade de Economia e Administração de Viena; fundador e Editor-chefe do Journal of Geographical Systems, Geographical Systems, Analysis, Theory and Decision, Springer), o ECTQG tem sabido definir o seu caminho e, mais importante ainda, o ECTQG e seus colaboradores têm mantido fidelidade científica.

Pela sua importância, que aqui se tentou relatar, no domínio mais circunspecto da geografia aplicada, ou mais lato, sobre o aprofundamento teórico dos estudos geográficos, aconselhamos a todos os geógrafos e àqueles que se interessam pela Geografia, a estarem atentos e participarem no próximo ECTQG (XV ECTQG'07), organizado pelo Instituto de Geografia - Faculdade de Geociências e Ambiente da Universidade de Lausanne, em Montreux, na Suiça, de 7 a 11 de Setembro de 2007. Para mais informações pode consultar-se o site http://www2.unil.ch/ectqg07/index.html 